\title{
ATIVIDADE ANTIOXIDANTE, COMPOSIÇÃO QUIIMICA E CONSERVAÇÃO DO MARACUJÁ-AMARELO EMBALADO COM FILME PVC ${ }^{1}$
}

\author{
MARIA CRISTINA COPELLO ROTILI' ${ }^{2}$, JESSICA ARIANE VORPAGEL ${ }^{3}$, \\ GILBERTO COSTA BRAGA ${ }^{4}$, ODAIR JOSÉ KUHN ${ }^{5}$, ARIANE BUSCH SALIBE ${ }^{6}$
}

RESUMO-O objetivo deste trabalho foi avaliar as características químicas e a conservação do maracujáamarelo embalado com filme de PVC durante o armazenamento refrigerado a $5{ }^{\circ} \mathrm{C}$. Atividade antioxidante (DPPH e TEAC), compostos fenólicos totais, $\beta$-caroteno e ácido ascórbico do suco do fruto foram os parâmetros químicos avaliados. As estimativas de perda de massa, enrugamento, cor e sintomas de patógenos foram utilizadas no estudo de conservação. As avaliações foram realizadas em intervalos de 10 dias, durante 40 dias. De acordo com os resultados, o teor de fenólicos totais aumentou durante o armazenamento, com variações entre 20,10 e 21,29 mg EAG $100 \mathrm{~mL}^{-1}$. O conteúdo de ácido ascórbico aumentou até o $20^{\circ}$ dia de armazenamento $\left(33,58 \mathrm{mg} 100 \mathrm{~mL}^{-1}\right)$, mas seguiu com decréscimos até o $40^{\circ}$ dia $\left(21,67 \mathrm{mg} 100 \mathrm{~mL}^{-1}\right)$. Independentemente do uso de PVC, o conteúdo de $\beta$-caroteno não variou durante o armazenamento. As atividades antioxidantes DPPH e TEAC do suco diminuíram durante o armazenamento. Não foram encontradas correlações positivas entre as atividades DPPH e TEAC e o teor de fenólicos totais, sugerindo que este último não contribui para a atividade antioxidante do suco do maracujá. O uso da embalagem de PVC não influenciou positivamente a atividade antioxidante e os teores de fenólicos totais e ácido ascórbico do suco do maracujá-amarelo durante seu armazenamento. A embalagem de PVC não inibiu sintomas de desenvolvimento de patógenos por até 30 dias de armazenamento, a $5{ }^{\circ} \mathrm{C}$, mas reduziu a perda de massa fresca e o enrugamento do fruto, proporcionando condições ótimas de comercialização por até 20 dias.

Termos para indexação: Passiflora edulis, refrigeração, patógenos, qualidade física.

\section{ANTIOXIDANT ACTIVITY, CHEMICAL COMPOSITION AND CONSERVATION OF YELLOW PASSION FRUIT PACKED WITH PVC FILM}

\begin{abstract}
The aim of this study was to evaluate the chemical characteristics and conservation of yellow passion fruit packed with PVC film during refrigerated at $5{ }^{\circ} \mathrm{C}$. Antioxidant activity (DPPH and TEAC), total phenolic compounds, $\beta$-carotene and ascorbic acid of the fruit juice were the chemical parameters. Estimations of weight loss, wrinkling, color and symptoms of pathogens were used in the conservation study. The evaluations were performed in 10-day intervals for 40 days. According to the results, the total phenolic content increased during storage, varying between 20.10 and $21.29 \mathrm{mg}$ EAG $100 \mathrm{~mL}^{-1}$. The contents

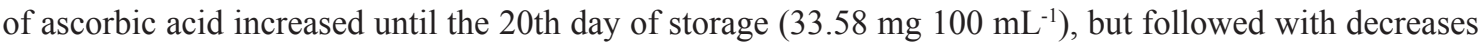
until the 40th day $\left(21.67 \mathrm{mg} 100 \mathrm{~mL}^{-1}\right)$. Regardless of the use of PVC, $\beta$-carotene did not change during storage. The TEAC and DPPH antioxidant activity in juice decreased during storage. The DPPH and TEAC antioxidant activity did not correlate positively with total phenolics, suggesting that phenolic compounds do not contribute to the antioxidant activity of passion fruit juice. The use of PVC packaging did not influence positively on the antioxidant activity and the contents of total phenolics and ascorbic acid of yellow passion fruit juice during storage. The PVC did not inhibit the pathogens-degradation symptoms for up to 30 days of storage, at $5{ }^{\circ} \mathrm{C}$, but reduced the weight loss and wrinkling of the fruit, providing optimal conditions of merchantability for up to 20 days.
\end{abstract}

Index terms: Passiflora edulis, refrigeration, pathogens, physical quality.

\footnotetext{
${ }^{1}$ (Trabalho 109-13). Recebido em: 13-03-2013. Aceito para publicação em: 12-11-2013.

${ }^{2}$ Mestranda em Agronomia, PPGA, Centro de Ciências Agrárias/CCA, Universidade Estadual do Oeste do Paraná/Unioeste, Cx.p. 1008, 85960-000, Marechal Cândido Rondon, PR., E-mail: crotili@ig.com.br

${ }^{3}$ Graduanda em Agronomia, CCA, Unioeste, E-mail: jessica-vorpagel@hotmail.com

${ }^{4}$ Prof. Dr., CCA, Unioeste, E-mail: gcb1506@gmail.com

${ }^{5}$ Prof. Dr.,, CCA, Unioeste, E-mail: ojkuhn@gmail.com

${ }^{6}$ Profa $^{\mathrm{a}}$. Dr ${ }^{\mathrm{a}}$., Departamento de Biotecnologia Vegetal, Universidade Federal de São Carlos/UFSCAR, Campus de Araras, Rodovia Anhanguera, Km 174, s/n, 13600-970, Araras, São Paulo, Brasil. E-mail: absalibe@ig.com.br
} 


\section{INTRODUÇÃO}

Entre as espécies do gênero Passiflora, o maracujá-amarelo (Passiflora edulis f. flavicarpa Deg.) é o mais cultivado no Brasil e muito apreciado pelo aroma e sabor intensos de seu suco (SAMPAIO et al., 2008). Na composição química do suco, os frutos são ricos em minerais, vitaminas (DHAWAN et al., 2004), compostos fenólicos (TALCOTT et al., 2003) e carotenoides (WONDRACEK et al., 2011), que contribuem para os seus atributos sensoriais e nutricionais. Entre os carotenoides presentes, ao $\beta$-caroteno é atribuída a cor amarelada típica do suco (UENOJO et al., 2007). No aspecto nutricional, tem sido dado grande destaque à atividade antioxidante de compostos presentes nas frutas, por possuírem potencial de reduzir o nível de estresse oxidativo celular (RUFINO et al., 2009; HASSIMOTTO et al., 2005). Segundo Pietta (2000), antioxidantes são substâncias que reduzem o dano oxidativo das células, bloqueando os radicais livres e prevenindo a formação de algumas doenças.

$\mathrm{O}$ acúmulo de vitaminas, de compostos fenólicos e de carotenoides em frutos é variável e depende, entre muitos fatores, do estádio de maturação e das condições de armazenamento (VEBERIC et al., 2008). Tais compostos são sintetizados por vias metabólicas durante o desenvolvimento e a maturação de frutos com diferentes funções bioquímicas e físicas no órgão, participando em mecanismos de defesa, fator de atratividade e como antioxidantes (POURCEL et al., 2007).

$\mathrm{Na}$ fase pós-colheita, diversas e importantes alterações decorrentes de fatores de natureza física, fisiológica e patológica podem ocorrer, as quais interferem na conservação e nas características físicas, químicas e nutricionais das frutas. Para uma boa aceitação dos consumidores, os frutos devem estar túrgidos, com a casca amarela, lisa ou pouco enrugada e sem manchas, além da ausência de danos decorrentes da presença de fungos ou ataque de insetos (FISCHER et al., 2007).

$\mathrm{Na}$ etapa de conservação pós-colheita, as alterações físicas e químicas nos frutos podem ser diminuídas através do uso de embalagens plásticas com modificação passiva ou ativa da atmosfera interna (ARRUDA et al., 2011). A modificação passiva da atmosfera no interior da embalagem ocorre pela presença da barreira artificial à difusão de gases e vapor d'água em torno do produto, que resulta em redução do nível de $\mathrm{O}_{2}$ e aumento do nível de $\mathrm{CO}_{2}$ devido ao metabolismo do órgão, além do aumento na pressão de vapor d'água (JERONIMO et al., 2007). O uso de embalagens plásticas tem sido estudado por vários pesquisadores, com a finalidade de diminuir o desenvolvimento de patógenos e o enrugamento, e aumentar a vida útil de frutas (SINGH; SINGH, 2012; BASTIAANSE et al., 2010; LIMA et al., 2005).

O uso de filme plástico de PVC (policloreto de vinila) é prático e de baixo custo, e tem sido muito utilizado no armazenamento de frutas e hortaliças, principalmente quando associado ao armazenamento refrigerado. Sua eficiência na conservação pós-colheita de frutos tem sido reportada (CIA et al., 2010; MOTA et al., 2006; MOTA et al., 2003). Entretanto, para o maracujá-amarelo, nenhuma pesquisa foi realizada sobre respostas bioquímicas, com abordagem sobre composição e atividade antioxidante do fruto, frente ao uso da embalagem de PVC. Neste contexto, o objetivo deste trabalho foi avaliar a influência do armazenamento refrigerado em embalagem de PVC, na atividade antioxidante, nos teores de compostos fenólicos totais, carotenoides e ácido ascórbico, e nas qualidades física e microbiológica do maracujáamarelo.

\section{MATERIAL E MÉTODOS}

Foram estudados frutos de maracujá-amarelo obtidos de pomar comercial, no município de Corumbataí do Sul-PR, localizado a $24^{\circ} 06^{\prime} 03^{\prime \prime}$ de latitude sul, $52^{\circ} 07^{\prime} 12$ " de longitude oeste e a $601 \mathrm{~m}$ de altitude. Depois de colhidos, em abril de 2011, os frutos foram selecionados por uniformidade de tamanho e ausência de defeitos. Depois foram lavados e higienizados com solução de hipoclorito de sódio a $0,1 \mathrm{~mL} \mathrm{~L}^{-1}$, por imersão durante 3 minutos em temperatura ambiente e posterior secagem com papel toalha. Foram escolhidos frutos em início de amadurecimento, ou seja, cor da casca predominantemente verde.

Os frutos foram acondicionados em bandejas de poliestireno expandido, contendo dois frutos cada. Um grupo foi embalado com filme de PVC esticável (12 $\mu \mathrm{m}$, Flexibag), e outro foi mantido em atmosfera ambiente (não embalado). Depois foram armazenados em câmara climática a $5{ }^{\circ} \mathrm{C}\left( \pm 2{ }^{\circ} \mathrm{C}\right)$ e umidade relativa de $77 \%( \pm 3 \%)$, e avaliados em intervalos de 10 dias, num período de 40 dias. Foi utilizado o delineamento inteiramente casualizado, com cinco repetições.

Nas análises destrutivas, os frutos foram cortados transversalmente com uma faca de aço inoxidável, e a polpa retirada, sendo separado o suco da semente com peneira plástica. As amostras de suco foram acondicionadas em tubo plástico com tampa 
e armazenadas a $-24^{\circ} \mathrm{C}$.

Para a determinação da atividade antioxidante, o extrato foi preparado com a adição de $2,0 \mathrm{~mL}$ de suco em 7,0 mL do extrator (etanol a $80 \%$ ). Este extrato foi homogeneizado em Vórtex por 30 seg., em seguida, dispersado com Ultraturrax por um minuto, centrifugado a $2.000 . \mathrm{g}$ por $10 \mathrm{~min}$ e filtrado em papel qualitativo $(15 \mu \mathrm{m})$. Todo o procedimento ocorreu no escuro e em triplicata. Ao final, os extratos foram armazenados a $-24^{\circ} \mathrm{C}$.

A atividade antioxidante do suco foi avaliada pela capacidade de sequestro do radical DPPH (2,2-diphenyl-1-picrylhydrazyl) e pelo método TEAC (Trolox Equivalent Antioxidant Capacity) que estima a capacidade da amostra em sequestrar o radical $\mathrm{ABTS}^{-+}\left[2,2^{\prime}\right.$-azino-bis-(3-ethylbenzthiazoline-6-sulfonic acid)]. A determinação da atividade antioxidante DPPH foi feita segundo o indicado por De Ancos et al. (2002), em que $150 \mu \mathrm{L}$ do extrato foram adicionados a $850 \mu \mathrm{L}$ da solução de DPPH $\left(60 \mu \mathrm{Mol} \mathrm{L}^{-1}\right)$, e deixados em repouso por 30 minutos, no escuro. Procedeu-se à leitura da absorbância em espectrofotômetro (BEL Photonics, SP1105) a $515 \mathrm{~nm}$, tendo-se o etanol como branco. Utilizou-se para a curva de calibração, padrão de ácido ascórbico a $10 ; 15 ; 24 ; 37 ; 56$ e $85 \mu \mathrm{g} \mathrm{mL}^{-1}$. A partir da equação ajustada, realizou-se o cálculo da atividade antioxidante, em equivalente ácido ascórbico (EAA), sendo expressa em mg EAA 100 $\mathrm{mL}^{-1}$ de suco.

A atividade antioxidante TEAC foi determinada de acordo com Stratil et al. (2006), com modificações. $\mathrm{O}$ radical $\mathrm{ABTS}^{++}$foi formado pela reação de $140 \mathrm{mMol} \mathrm{L}^{-1}$ de persulfato de potássio com $7 \mathrm{mMol} \mathrm{L}^{-1}$ de $\mathrm{ABTS}^{++}$, armazenado no escuro e à temperatura ambiente, por 16 horas. $\mathrm{O}$ radical $\mathrm{ABTS}^{*+}$ foi diluído com etanol até absorbância entre 0,700 e 0,734 ( $\pm 0,005)$. Em ambiente escuro, transferiu-se uma alíquota de $30 \mu \mathrm{L}$ de cada diluição do extrato para tubos de ensaio e adicionaram-se 3,0 $\mathrm{mL}$ do radical $\mathrm{ABTS}^{++}$. Realizou-se a leitura a 734 nm após 6 minutos de reação, tendo-se o etanol como branco. A curva-padrão foi ajustada com Trolox [(+/-)-6-hydroxy-2,5, 7,8-tetramethyl-chroman-2carboxylic acid] nas concentrações 0,$02 ; 0,12 ; 0,25$; 0,37 e $0,50 \mu \mathrm{g} \mathrm{mL}^{-1}$. Os resultados da atividade antioxidante do suco foram calculados de acordo com a equação ajustada com o padrão e expressos em equivalente Trolox ( $\mu$ g ETrolox $100 \mathrm{~mL}^{-1}$ de suco).

$\mathrm{O}$ teor de compostos fenólicos totais foi determinado de acordo com Singleton et al. (1999). Amostras de 2,2 $\mathrm{mL}$ de suco do maracujá foram transferidas para tubos de ensaio, onde foram adicionadas de $8,0 \mathrm{~mL}$ de etanol. Os tubos foram submetidos à agitação por 2 minutos e depois centrifugados a $2.000 . \mathrm{g}$ durante 10 minutos. Os extratos foram filtrados em papel qualitativo (15 $\mu \mathrm{m})$. Uma alíquota de $0,5 \mathrm{~mL}$ da amostra foi transferida para tubo de ensaio, com adição de 2,5 $\mathrm{mL}$ do Reagente de Folin-Ciocalteau a 10 \% (10:90; $\mathrm{v} / \mathrm{v}$ ), e deixado em repouso durante 5 minutos. Em seguida, foram adicionados $2,0 \mathrm{~mL}$ de carbonato de sódio a $4 \%(4: 96 ; \mathrm{m} / \mathrm{v})$, e os tubos, deixados em repouso por 2 horas, no escuro. A absorbância foi medida em espectrofotômetro a $740 \mathrm{~nm}$. Foi utilizada curva- padrão de ácido gálico, nas concentrações de 5 a $80 \mu \mathrm{g} \mathrm{mL}^{-1}$. Os resultados foram expressos em equivalente ácido gálico (mg EAG $100 \mathrm{~mL}^{-1}$ de suco).

$O$ teor de $\beta$-caroteno foi determinado conforme método de Nagata e Yamashita (1992). Uma amostra de $1,0 \mathrm{~mL}$ de suco foi adicionada a 10 $\mathrm{mL}$ de solvente ( $6 \mathrm{~mL}$ de hexano $/ 4 \mathrm{~mL}$ de acetona). $\mathrm{O}$ extrato foi homogeneizado com Ultraturrax durante um minuto e centrifugado a 2.000.g durante 10 minutos. O sobrenadante foi recolhido para leitura da absorbância. Os teores nas amostras foram calculados utilizando-se da seguinte equação:

$\beta$-caroteno $=0,216 A_{663}-1,22 A_{645}-0,304 A_{505}+0,452 A_{453}$,

em que: $A_{663}, A_{645}, A_{505}$ e $A_{453}$ são as absorbâncias da leitura da amostra a $663 ; 645 ; 505$ e $453 \mathrm{~nm}$, respectivamente. Os resultados foram expressos em mg $100 \mathrm{~mL}^{-1}$ de suco.

$\mathrm{O}$ teor de ácido ascórbico foi determinado por titulação com 2,6-dicloro-fenol-indofenol (DCFI), com as modificações propostas por Benassi e Antunes (1988). Os resultados foram expressos em mg $100 \mathrm{~mL}^{-1}$ de suco.

$O$ índice de degradação patogênica foi determinado de acordo com Cao et al. (2011). As amostras de cada repetição foram avaliadas visualmente, e a incidência de patógenos foi estimada por um índice de acordo com uma escala de quatro pontos, em que: $0=$ sadio ou nenhum fruto atacado; $1=$ leve incidência, menor que $25 \%$ da superfície dos frutos atacados; 2 = incidência moderada, cobrindo superfície maior que $25 \%$, mas inferior a $50 \%$ da superfície dos frutos; 3 = incidência severa, cobrindo mais de $50 \%$ da superfície dos frutos. O índice de degradação por patógenos foi calculado de acordo com a seguinte fórmula:

$$
\begin{gathered}
\text { Índice de degradação patogênica }= \\
\left(1 \times N_{1}+2 \times N_{2}+3 \times N_{3}\right) \times[100 \div(3 \times N)],
\end{gathered}
$$

em que: $N$ é o número total de frutos avaliados $(10$ frutos) e $N_{1}, N_{2}$ e $N_{3}$ o número de frutos atacados por 
nota de incidência (1;2 ou 3$)$.

A qualidade física do maracujá-amarelo foi avaliada segundo a perda de massa fresca, enrugamento e cor da casca do fruto. A perda de massa foi determinada através da diferença entre a massa fresca inicial das unidades experimentais e a massa no dia da amostragem, expressa em \%. $\mathrm{O}$ enrugamento foi determinado subjetivamente, através de exame visual, utilizando índice numérico de escalas de notas, em que: $1=$ casca totalmente lisa; $2=$ mais lisa do que enrugada; $3=$ porções de casca igualmente lisa e enrugada; 4=mais enrugada do que lisa; $5=$ totalmente enrugada. A variação da cor da casca foi determinada subjetivamente, através de índice de escala numérica, variando de $1(100 \%$ da casca verde) até 5 (100\% amarela). Todas as análises foram realizadas em triplicata.

Foi aplicada a análise de variância, e aos parâmetros que apresentaram efeito significativo pelo teste $\mathrm{F}$, suas médias $(\mathrm{n}=5)$ foram comparadas pelo teste Fisher-LSD. A análise de correlação linear de Pearson foi aplicada entre as variáveis. O nível de significância a $\mathrm{p}<0,05$ foi utilizado em todas as análises.

\section{RESULTADOS E DISCUSSÃO}

De acordo com a análise de variância (dados não apresentados), não houve efeito significativo $(p<0,05)$ do fator embalagem para fenólicos totais e ácido ascórbico do suco do maracujá-amarelo, ou seja, a embalagem de PVC não interferiu nessas variáveis durante o armazenamento. Acréscimos significativos de fenólicos totais ocorreram durante o armazenamento (Figura 1a), cujos resultados médios aumentaram de 20,10 para 21,29 mg EAG 100 $\mathrm{mL}^{-1}$ durante o armazenamento. Rotili et al. (2013) também encontraram aumento no teor de fenólicos totais do maracujá-amarelo durante o armazenamento sob diferentes temperaturas.

Compostos fenólicos são substâncias do metabolismo secundário do fruto, e sua variação, durante a etapa pós-colheita, muitas vezes está relacionada à fisiologia normal da maturação (TAIZ; ZEIGER, 2006) ou como resposta a estresses ambientais envolvendo temperatura, transpiração, oxigênio e patógenos (ROUSSOS et al., 2007; SOARES et al., 2008).

A análise de variância mostrou também que não houve efeito significativo do tempo de armazenagem sobre o conteúdo de $\beta$-caroteno, indicando que este componente se manteve estável no suco de maracujá durante o armazenamento. Uenojo et al (2007) também indicaram que os teores de carotenoides em frutos são relativamente estáveis durante a etapa pós-colheita, sem grandes mudanças até o início da senescência. Frutos embalados com PVC apresentaram suco com teor de $\beta$-caroteno significativamente menor que os frutos não embalados, cujas médias gerais foram 0,33 e 0,44 $\mathrm{mg} 100 \mathrm{~mL}^{-1}$, respectivamente (Figura $1 \mathrm{~b}$ ).

A Figura 1c indica que houve aumento significativo no teor de ácido ascórbico até o $20^{\circ}$ dia de armazenamento $\left(33,58 \mathrm{mg} 100 \mathrm{~mL}^{-1}\right)$, seguido de decréscimo até o $40^{\circ}$ dia $\left(21,67 \mathrm{mg} 100 \mathrm{~mL}^{-1}\right)$. Segundo Stevens et al. (2008), a manutenção dos níveis de ácido ascórbico em órgãos vegetais é rigidamente controlada por reações de síntese, degradação, reciclagem e transporte dentro da célula. Neste caso, os resultados sugerem que, após 20 dias de armazenamento a $5{ }^{\circ} \mathrm{C}$, a redução no teor de ácido ascórbico possa ter ocorrido devido à prevalência de processos degradativos.

A embalagem de PVC não interferiu na atividade antioxidante DPPH até o $30^{\circ}$ dia de armazenamento (Figura 2a), mas após 40 dias, os frutos embalados apresentaram atividade antioxidante $(28,50 \mathrm{mg}$ EAA $100 \mathrm{~mL}^{-1}$ ) significativamente menor que os frutos não embalados $\left(22,29 \mathrm{mg}\right.$ EAA $\left.100 \mathrm{~mL}^{-1}\right)$. De forma similar, frutos embalados com PVC exibiram menor atividade antioxidante TEAC aos 20 e 30 dias de armazenamento, com valores de 61,47 e $58,16 \mathrm{mg}$ ETrolox $100 \mathrm{~mL}^{-1}$, respectivamente, enquanto frutos não embalados exibiram, nos mesmos períodos, 68,50 e 64,38 mg ETrolox $100 \mathrm{~mL}^{-1}$, respectivamente. Esses resultados indicam que o uso da embalagem de PVC não tem influência sobre a atividade antioxidante do suco do maracujá.

A modificação passiva da atmosfera interna da embalagem era esperada com o uso do filme plástico, devido à atividade respiratória de frutos durante o armazenamento (JERONIMO et al., 2007; LIMA et al., 2005). Entretanto, Cia et al. (2010) verificaram mudanças muito pequenas na atmosfera (O2 e CO2) da embalagem de PVC durante o armazenamento refrigerado de uva, quando comparado com outros filmes plásticos, como o polietileno, e sua não interferência no metabolismo deste fruto. É possível que esta baixa eficiência do $\mathrm{PVC}$, como barreira a gases (O2 e $\mathrm{CO} 2)$, possa explicar a falta de influência na composição e na atividade antioxidante verificados neste trabalho.

As atividades antioxidantes DPPH e TEAC do suco dos frutos diminuíram significativamente durante $o$ armazenamento (Figuras $2 \mathrm{a}$ e 2b). A DPPH decresceu de 32,23 para $28,50 \mathrm{mg}$ EAA $100 \mathrm{~mL}^{-1}$ nos frutos não embalados, e de 34,48 para $22,29 \mathrm{mg}$ EAA $100 \mathrm{~mL}^{-1}$ nos embalados com PVC. Rotili et al. (2013) também encontraram redução da atividade 
antioxidante DPPH em maracujá-amarelo não embalado e armazenado por 30 dias, em diferentes temperaturas. Para a atividade antioxidante TEAC, os decréscimos foram de 74,32 para 56,52 mg ETrolox $100 \mathrm{~mL}^{-1}$ nos frutos não embalados e de 74,07 para 57,67 mg ETrolox $100 \mathrm{~mL}^{-1}$ nos embalados com PVC. Os resultados indicam a prevalência de reações oxidativas no suco do maracujá durante seu armazenamento, com reflexos degradativos na atividade antioxidante do suco.

Muitos compostos com caráter antioxidante estão presentes na composição de frutos, alguns dos quais estão envolvidos com a manutenção dos níveis normais de radicais livres na célula, e outros com mecanismos de proteção do tecido contra patógenos (ROUSSOS et al., 2007; SOARES et al., 2008). No entanto, os resultados da correlação linear de Pearson mostraram coeficientes negativos entre as atividades antioxidantes DPPH e TEAC, e fenólicos totais $(-0,66$ e $-0,70$, respectivamente), sugerindo que fenólicos totais presentes no suco do maracujá-amarelo não contribuem para sua atividade antioxidante. De forma similar, $\beta$-caroteno e ácido ascórbico também não se correlacionaram com DPPH e TEAC, cujos coeficientes para $\beta$-caroteno foram de $-0,13$ e 0,19 (respectivamente), e para ácido ascórbico -0,12 e 0,00 (respectivamente). Trabalhos científicos com outros frutos mostraram correlações positivas entre fenólicos totais e atividade antioxidante DPPH, como em nêsperas (GRUZ et al., 2011) e maçãs (LEJA et al., 2003) armazenadas.

A qualidade microbiológica dos frutos foi avaliada com base no índice de degradação patogênica, determinado durante o armazenamento e representado numa escala percentual, conforme mostrado na Figura 3. Os dados observados refletem o nível de degradação por patógenos de acordo com a severidade de ataque superficial em cada fruto e com o número de frutos atacados. $\mathrm{O}$ fungo Penicillium ssp. foi identificado, por análise microscópica, como sendo o maior responsável pelos sintomas.

Em ambas as atmosferas de armazenagem, aumentos significativos no índice de degradação patogênica foram verificados apenas após 30 dias de armazenagem, com $16,67 \%$ de sintomas nos frutos (Figura 3), mostrando que, neste período e sob refrigeração, o uso do PVC não foi eficiente em inibir o desenvolvimento de sintomas de patógenos. No entanto, um possível efeito inibidor da ação de patógenos foi verificado aos 40 dias, quando acréscimo no índice de degradação patogênica ocorreu nos frutos não embalados, atingindo $50 \%$ de sintomas superficiais, enquanto nos frutos embalados com PVC este índice manteve-se em 16,67\%. A aplicação da atmosfera modificada passiva, pelo uso de filmes plásticos, para reduzir a degradação póscolheita de frutas por patógenos, também tem sido reportada por diferentes autores (ARRUDA et al., 2011; JERONIMO et al., 2007; LIMA et al., 2005).

De acordo com a Figura $4 a$, frutos embalados com PVC apresentaram perda de massa de 10,43\% aos 40 dias de armazenamento, enquanto nos frutos não embalados a perda de massa foi de $43,93 \%$. De forma similar (Figura $4 \mathrm{~b}$ ), frutos embalados com PVC tiveram índice de enrugamento 3 (porções de casca igualmente lisa e enrugada) até os 40 dias, e frutos não embalados índice 5 (superfície da casca totalmente enrugada). Esses resultados indicam que o uso da embalagem de PVC foi significativamente eficiente em reduzir a perda de massa fresca e o enrugamento dos frutos durante o armazenamento. Resultados semelhantes também foram verificados por Mota et al. (2003; 2006).

De acordo com Cia et al. (2010), a perda de massa fresca de frutos embalados com filmes plásticos está diretamente relacionada à taxa de transmissão de vapor d'água da embalagem, ou seja, quanto menor a taxa de transmissão, menor o déficit de pressão de vapor d'água e maior a umidade relativa no interior da embalagem, o que reduz a taxa de transpiração das frutas. Da mesma forma, a forte correlação linear $(0,94)$ verificada entre perda de massa fresca e enrugamento revela a associação direta entre essas duas variáveis. O controle da perda de massa e do enrugamento do maracujá-amarelo tem fundamental importância, pois seu comércio é feito por peso e pela aparência, justificando o uso do PVC.

$\mathrm{Na}$ análise de variância, constatou-se que não houve efeito significativo do fator embalagem sobre a cor da casca do maracujá, sugerindo que o uso do PVC também não interferiu nos processos metabólicos envolvidos nas mudanças de cor do fruto, muito provavelmente devido à baixa eficiência do PVC como barreira a gases. Acréscimos nos índice de cor dos frutos foram verificados durante o armazenamento refrigerado (Figura $4 \mathrm{c}$ ), variando de 1,5 (entre 100 e $75 \%$ da casca cor verde) a 2,9 (aproximadamente 50\% da casca amarela). Dentre as diversas reações metabólicas da maturação, a degradação de clorofila e a síntese de outros pigmentos, como os carotenoides de cor amarela do maracujá (SILVA et al., 2008), refletem o aumento da cor amarela da casca e são marcantes nesta etapa do desenvolvimento do fruto.

Não houve influência da embalagem de PVC nos resultados de cor da casca ao longo do armazenamento (Figura 4c), ou seja, não 
houve interferência nos processos metabólicos envolvidos nas mudanças de cor do maracujá, cujos índices foram significativamente crescentes durante o armazenamento refrigerado, variando de 1,5 (entre 100 e $75 \%$ da casca cor verde) a 2,9 (aproximadamente $50 \%$ da casca amarela). Este avanço na mudança de cor da casca reflete processos fisiológicos envolvendo a respiração, o que sugere baixa eficiência da embalagem de PVC como barreira ao $\mathrm{O} 2$, mas foi eficiente como barreira ao vapor de água, pois reduziu a perda de massa e o enrugamento.
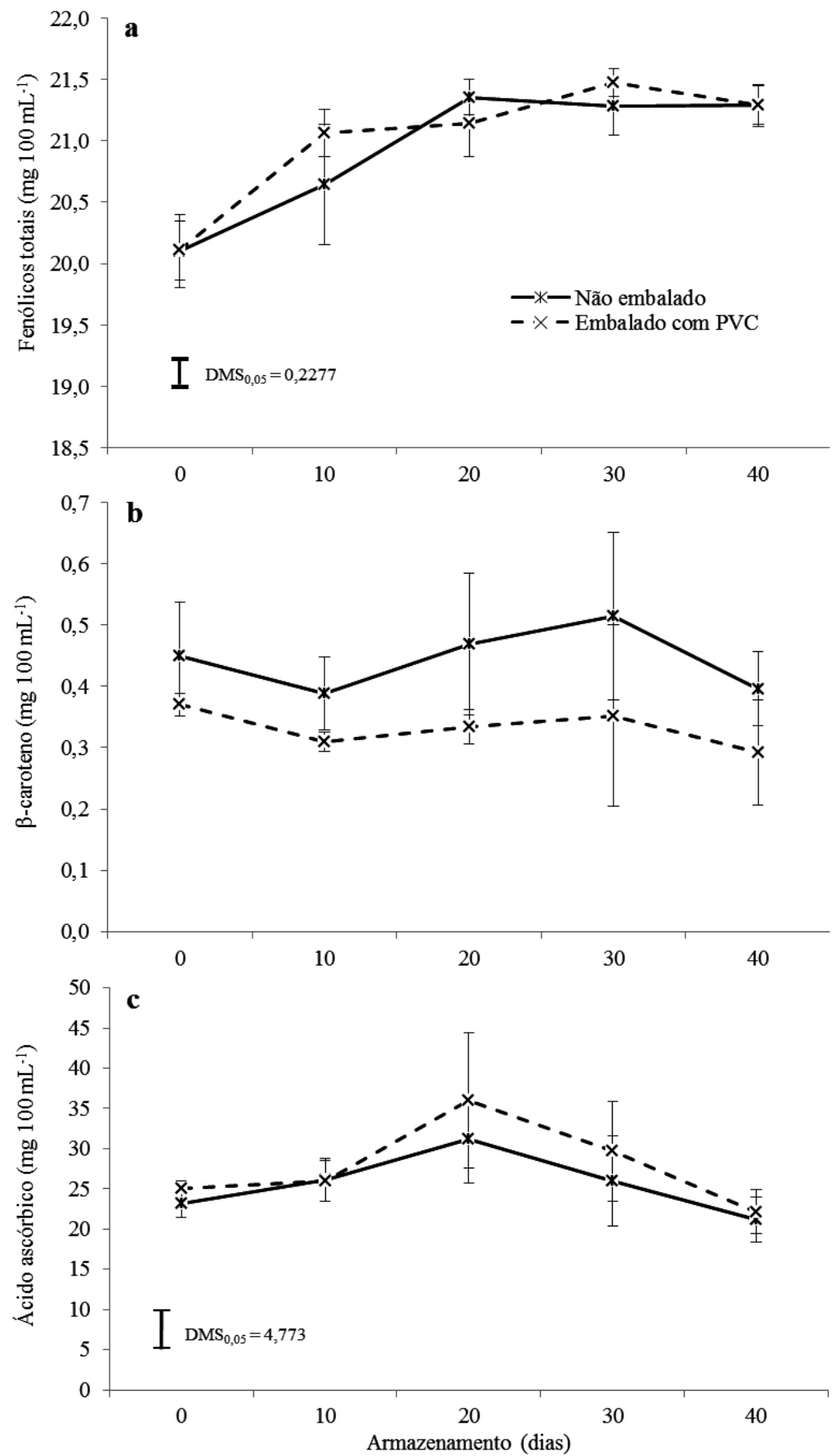

FIGURA 1- Fenólicos totais (a), $\beta$-caroteno (b) e ácido ascórbico (c) no suco de maracujás-amarelos embalados ou não em filme de PVC e armazenados a $5{ }^{\circ} \mathrm{C}$ e $77 \%$ UR. (DMS = diferença mínima significativa, $\mathrm{n}=5$ ). 

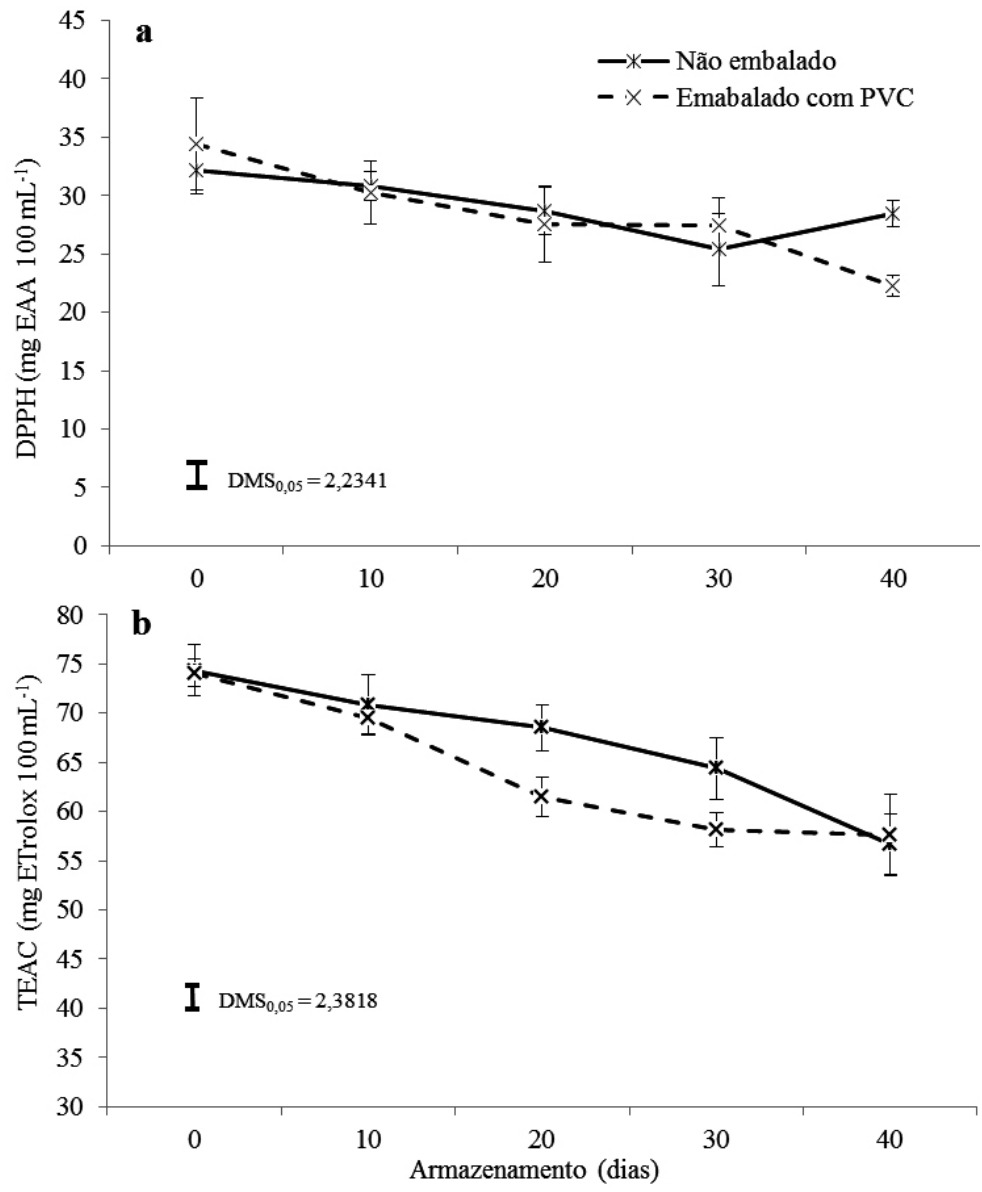

FIGURA 2- Atividade antioxidante DPPH (a) e TEAC (b) no suco de maracujás-amarelos embalados ou não com filme de PVC e armazenados a $5{ }^{\circ} \mathrm{C}$ e $77 \%$ UR. (DMS = diferença mínima significativa, $\mathrm{n}=5)$.

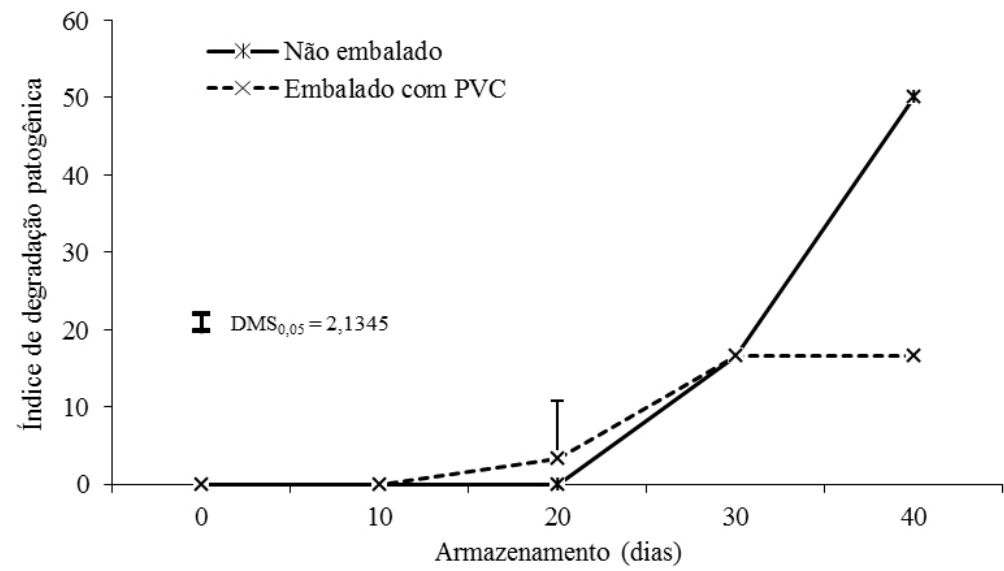

FIGURA 3- Índice de degradação por patógenos em frutos de maracujá-amarelo, embalados ou não com filme de PVC e armazenados a $5{ }^{\circ} \mathrm{C}$ e $77 \%$ UR. (DMS = diferença mínima significativa, $\mathrm{n}=5$ ). 

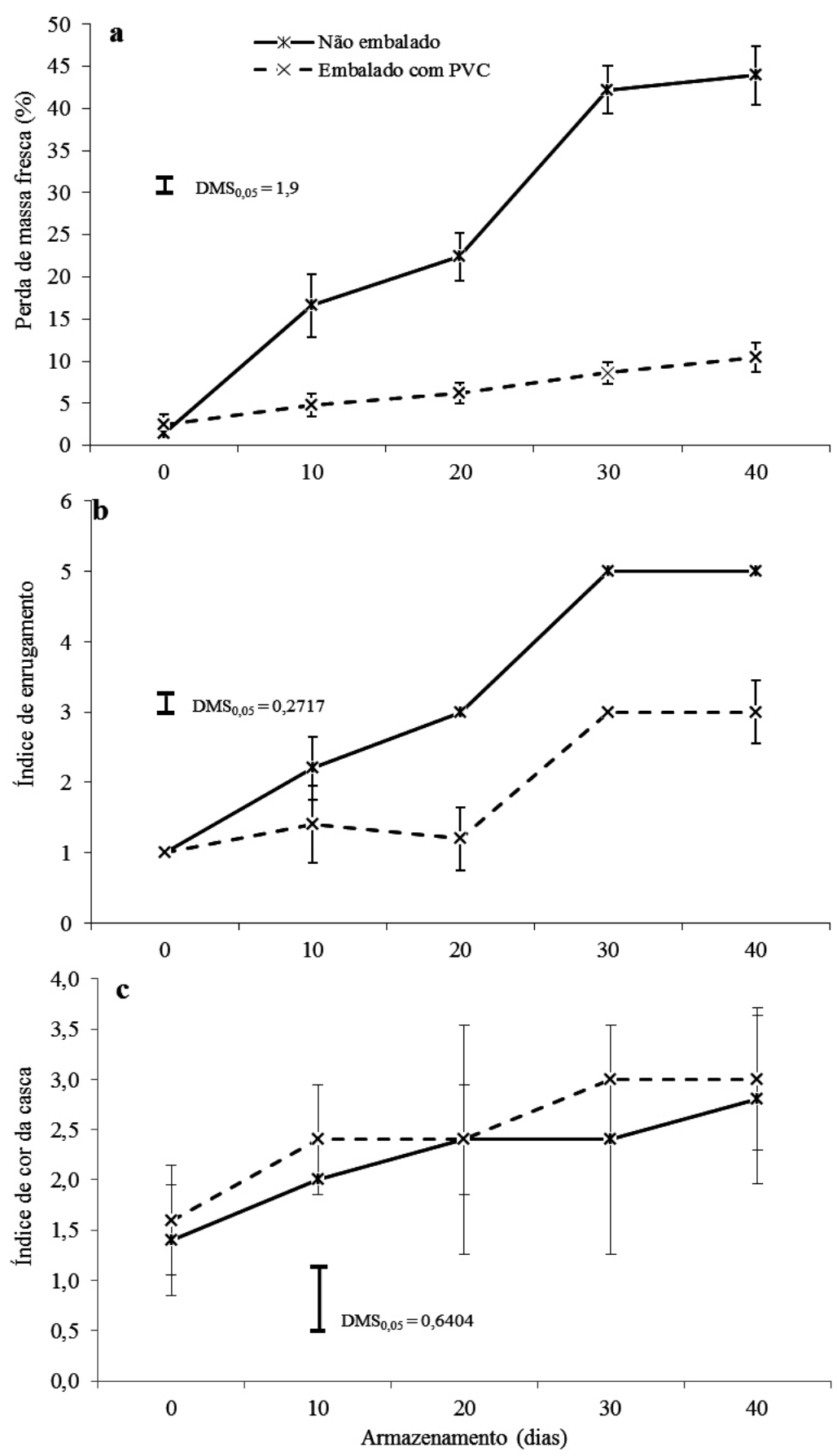

FIGURA 4 - Perda de massa fresca (a), enrugamento (b) e cor (c) do maracujá-amarelo embalado ou não com filme de PVC e armazenado a $5{ }^{\circ} \mathrm{C}$ e $77 \%$ UR. (DMS = diferença mínima significativa, $\mathrm{n}=5$ ). 


\section{CONCLUSÕES}

O uso da embalagem de PVC não influencia a atividade antioxidante e os teores de fenólicos totais e ácido ascórbico do suco do maracujá-amarelo durante seu armazenamento. A embalagem de PVC não inibiu sintomas de desenvolvimento de patógenos até 30 dias de armazenamento, mas reduz a perda de massa fresca e o enrugamento do fruto, proporcionando condições ótimas de comercialização até 20 dias de armazenamento a $5^{\circ} \mathrm{C}$.

\section{AGRADECIMENTOS}

Á CAPES, pelo auxílio financeiro de financiamento da bolsa de estudos da primeira autora.

\section{REFERÊNCIAS}

ARRUDA, M.C.; JACOMINO, A.P.; TREVISAN, M.J.; JERONIMO, E.M.; MORETTI, C.L. Atmosfera modificada em laranja 'Pera' minimamente processada. Bragantia, Campinas, v.70, n.3, p.664671, 2011.

BASTIAANSE, H.; BELLAIRE, L.L.; LASSOIS, L.; MISSON, C.; JIJAKLI, M.H. Integrated control of crown rot of banana with Candida oleophila strain $\mathrm{O}$, calcium chloride and modified atmosphere packaging. Biological Control, Amsterdam, v.53, n.1, p.100-107, 2010.

BENASSI, M.T.; ANTUNES, A.J. A comparison of metaphosphoric and oxalic acids as extractant solutions for the determination of vitamin $\mathrm{C}$ in selected vegetables. Brazilian Archives of Biology and Technology, Curitiba, v.31, n.4, p.507-513, 1988.

CAO, S.; HU, Z.; ZHENG, Y.; YANG, Z.; LU, B. Effect of BTH on antioxidant enzymes, radicalscavenging activity and decay in strawberry fruit. Food Chemistry, Barking, v.125, n.1, p.145-149, 2011.

CIA, P.; BENATO, E.A.; VALENTINI, S.R.T.; SANCHES, J.; PONZO, F.S.; FLÔRES, D.; TERRA, M.M. Atmosfera modificada e refrigeração para conservação pós-colheita de uva 'Niágara Rosada'. Pesquisa Agropecuária Brasileira, Brasília, v.45, p.1058-1065, 2010.
DE ANCOS, B.; SGROPPO, S.; PLAZA, L.; CANO, M.P. Possible nutritional and health-related value promotion in orange juice preserved by hightpressure treatment. Journal of the Science of Food and Agriculture, Oxford, v.82, n.8, p.790-796, 2002.

DHAWAN, K.; DHAWAN, S.; SHARMA, A. Passiflora: a review update. Journal of Ethnopharmacol, Limerick, v.94, n.1, p.1-23, 2004.

FISCHER, I.H.; ARRUDA, M.C.; ALMEIDA, A.M.; GARCIA, M.J.M.; JERONIMO, E.M.; PINOTTI, R.N.; BERTANI, R.M.A. Doenças e características físicas e químicas pós-colheita em maracujá-amarelo de cultivo convencional e orgânico no Centro-Oeste paulista. Revista Brasileira de Fruticultura, Jaboticabal, v.29, n.2, p.254-259, 2007.

GRUZ, J.; AYAZ, F.A.; TORUN, H.; STRNAD, M Phenolic acid content and radical scavenging activity of extracts from medlar (Mespilus germanica L.) fruit at different stages of ripening. Food Chemistry, Barking, v.124, n.1, p.271-277, 2011.

HASSIMOTTO, N.M.A.; GENOVESE, M.I.; LAJOLO, F.M. Antioxidant activity of dietary fruits, vegetables, and commercial frozen fruit pulps. Journal of Agriculture and Food Chemistry, Washington, v.53, n.8, p.2928- 2935, 2005.

JERONIMO, E.M.; BRUNINI, M.A.; ARRUDA, M.C.; CRUZ, J.C.S.; GAVA, G.J. de C.; SILVA, M.A. Qualidade de mangas 'Tommy Atkins' armazenadas sob atmosfera modificada. Ciência e Agrotecnologia, Lavras, v.31, n.4, p.1122-1130, 2007.

LEJA, M.; MARECZEK, A.; BEM, J. Antioxidant properties of two apple cultivars during long-term storage. Food Chemistry, Barking, v. 10 , n.3, p.303-307, 2003.

LIMA, L.C.; COSTA, S.M.; DIAS, M.S.C.; MARTINS, R.N.; RIBEIRO JR., P.M. Controle do amadurecimento de banana 'prata-anã', armazenada sob refrigeração e atmosfera modificada passiva com o uso do 1-metilciclopropeno. Ciência e Agrotecnologia, Lavras, v.29, n.2, p.476-480, 2005.

MOTA, W.F.; SALOMÃO, L.C.C.; CECON, P.R.; FINGER, F.L. Waxes and plastic film in relation to the shelf life of yellow passion fruit. Scientia Agricola, Piracicaba, v.60, n.1, p.51-57, 2003. 
MOTA, W.F.; SALOMÃO, L.C.C.; NERES, C.R.L.; MIZOBUTSI, G.P.; NEVES, L.L.M. Uso de cera-de-carnaúba e saco plástico poliolefínico na conservação pós-colheita do maracujá-amarelo. Revista Brasileira de Fruticultura, Jaboticabal, v.28, n.2, p.190-193, 2006.

NAGATA, M.; YAMASHITA, I. Simple method for simultaneous determination of chlorophyll and carotenoids in tomato fruit. Japanese Society for Food Science and Technology, Tokio, v.39, n.10, p.925-928, 1992.

PIETTA, P.G. Flavonoids as antioxidants. Journal of Natural Products, Cincinnati, v.63, n.7, p.10351042, 2000.

POURCEL, L.; ROUTABOUL, J.M.; CHEYNIER, V. Flavonoid oxidation in plants: from biochemical properties to physiological functions. Trends in Plant Science, London, v.12, n.1, p.29-36, 2007.

ROTILI, M.C.C.; COUTRO, S.; CELANT, V.M.; VORPAGEL, J.A.; BARP, F.K.; SALIBE, A.B.; BRAGA, G.C. Composição, atividade antioxidante e qualidade do maracujá-amarelo durante armazenamento. Semina: Ciências Agrárias, Londrina, v.34, n.1, p.227-240, 2013.

ROUSSOS, P.A.; MATSOUKIS, A.; PONTIKIS, C.A.; CHRONOPOULOU-SERELI, A. Relations of environmental factors with the phenol content and oxidative enzyme activities of olive explants. Scientia Horticulturae, Amsterdam, v.113, n.1, p.100-102, 2007.

RUFINO, M.S.M.; FERNANDES, F.A.N.; ALVES, R.E.; BRITO, E.S. Free radical-scavenging behavior of some north-east Brazilian fruits in a DPPH system. Food Chemistry, Barking, v.114, n.2, p.693-695, 2009.

SAMPAIO, A.C.; FUMIS, T.F.; ALMEIDA, A.M.; PINOTTI, R.N.; GARCIA, M.J.M.; PALLAMIN, M.L. Manejo cultural do maracujazeiro-amarelo em ciclo anual visando à convivência com o vírus do endurecimento dos frutos: um estudo de caso. Revista Brasileira de Fruticultura, Jaboticabal, v.30, n.2, p.343-347, 2008.
SILVA, T.V.; RESENDE, E.D.; VIANA, A.P.; PEREIRA, S.M.F.; CARLOS, L.A.; VITORAZI, L. Determinação da escala de coloração da casca e do rendimento em suco do maracujá-amarelo em diferentes épocas de colheita. Revista Brasileira de Fruticultura, Jaboticabal, v.30, n.4, p.880-884, 2008 .

SINGH, S.P.; SINGH, Z. Postharvest oxidative behaviour of 1-methylcyclopropene treated Japanese plums (Prunus salicina Lindell) during storage under controlled and modified atmospheres. Postharvest Biology and Technology, Amsterdam, v.74, n.5, p.26-35, 2012.

SINGLETON, V. L.; ORTHOFER, R.; LAMUELA, R. M. Analysis of total phenols and other oxidation substrates and antioxidants by means of FolinCiocalteau reagent. Methods in Enzymology, Orlando, v.299, n.1, p.152-178, 1999.

SOARES, M.; WELTER, L.; KUSKOSKI, E.M.; GONZAGA, L.; FETT, R. Compostos fenólicos e atividade antioxidante da casca de uvas Niágara e Isabel. Revista Brasileira de Fruticultura, Jaboticabal, v.30, n.1, p.59-64, 2008.

STEVENS, R.; PAGE, D.; GOUBle, B.; GARCHERY, C.; ZAMIR, D.; CAUSSE, M. Tomato fruit ascorbic acid content is linked with monodehydroascorbate reductase activity and tolerance to chilling stress. Plant, Cell and Environment, Oxford, v.31, n.8, p.1.086-1.096, 2008.

STRATIL, P.; KLEJDUS, B.; KUBÁŇ, V. Determination of total content of phenolic compounds and their antioxidant activity in vegetables evaluation of spectrophotometric methods. Journal of Agricultural and Food Chemistry, Easton, v.54, n.3, p.607-616, 2006.

TAIZ, L.; ZEIGER, E. Plant Physiology. $4^{\text {th }}$ ed. Sunderland: Sinauer Associates, 2006. 705p.

TALCOTT, S.T.; PERCIVAL, S.S.; PITTETMOORE, J.; CELORIA, C. Phytochemical composition and antioxidant stability of fortified yellow passion fruit (Passiflora edulis). Journal of Agricultural and Food Chemistry, Easton, v.51, n.4, p.935-941, 2003. 
UENOJO, M.; MARÓSTICA-JÚNIOR, M.R.; PASTORE, G.M. Carotenoides: propriedades, aplicações e biotransformação para formação de compostos de aroma, Química Nova, São Paulo, v.30, n.3, p.616-622, 2007.

VEBERIC, R.; COLARIC, M.; STAMPAR, F. Phenolic acids and flavonoids of fig fruit (Ficus carica L.) in the northem Mediterranean region. Food Chemistry, Barking, v.106, n.1, p.153-157, 2008.
WONDRACEK, D.C.; FALEIRO, F.G.; SANO, S.M.; VIEIRA, R.F.; AGOSTINI-COSTA, T.S. Composição de carotenoides em passifloras do cerrado. Revista Brasileira de Fruticultura, Jaboticabal, v.33, n.4, p.1222-1228, 2011. 